\title{
Game based physiotherapy for evidence based practice in children with juvenile idiopathic scoliosis
}

\author{
P Feistritzer-Gröbl ${ }^{1 *}$, A Nischelwitzer ${ }^{1}, V_{\text {Saraph }}^{2}$ \\ From 9th International Conference on Conservative Management of Spinal Deformities - SOSORT 2012 \\ Annual Meeting \\ Milan, Italy. 10-12 May 2012
}

\section{Background}

The performance of daily exercises of patients with "juvenile idiopathic scoliosis" (JIS) during the homebased exercise period is difficult to monitor; therefore the collection of evidence is a challenge.

\section{Aim}

The aim of this study was to use a specialised computer programme to guide, monitor and evaluate therapeutic exercises. With this programme, exercises are monitored so that they are carried out in a precise way, and children get a real-time feedback. Furthermore, data is recorded for further evaluation by the therapist.

\section{Methods}

Software and interfaces of a 3D input device were used to detect and measure smallest movements within a game scenario. To maintain motivation three different games were used. The study group were 20 children between 9 and 13 years old, with the diagnosis JIS (Cobb curve of $23^{\circ}+/-4^{\circ}$, bracing with Chêneau-braces). The children exercised six months according to the Schroth concept; two standardized exercises of this concept were carried out guided by the computer program. Data was recorded for each patient regarding exercises time and scores, exercise fault rates, stability, and mobility scores and selfefficacy scores. Correlations were calculated between different variables.

\section{Results}

Considering the changes of faults over time, it can be seen that the variable date had a highly-significant negative influence on mistakes in the $\mathrm{x}, \mathrm{y}$ and $\mathrm{z}$ - direction. (P-value: 0.004978)

\section{Conclusions}

The available computer program for patients with JIS is suitable for evaluating therapeutic exercises. The collected quantitative data gives valuable information on the exercise regime, and can be used to monitor and evaluate treatment process. Due to the monitoring of the precise performance of exercises, exercise times are used more efficiently. A randomized study with the same target group is currently being carried out to evaluate possibly different results of treatment with, or without, a computer game.

\section{Author details}

'University of Applied Sciences FH JOANNEUM, Graz, Austria. ${ }^{2}$ Department of Pediatric Surgery Medical University of Graz, Graz, Austria.

\section{Published: 3 June 2013}

\section{References}

1. Shumway-Cook AW, M H: Motor Control. Translating research into Clinical Practice. Philadelphia: Lippincott Williams \& Wilkins; 2007.

2. Sullivan KJ, Kantak SS, Burtner PA: Motor learning in children: feedback effects on skill acquisition. Phys Ther 2008, 88(6):720-732.

3. Chiviacowsky S, Wulf G, Laroque de Medeiros F, Kaefer A, Tani G: Learning benefits of self-controlled Knowledge of Results in 10-year-old children. 2008, 79(3)

doi:10.1186/1748-7161-8-S1-016

Cite this article as: Feistritzer-Gröbl et al:: Game based physiotherapy for evidence based practice in children with juvenile idiopathic scoliosis. Scoliosis 2013 8(Suppl 1):016.

\section{Furtist of author information is available at the end of the article}

(c) 2013 Feistritzer-Gröbl et al; licensee BioMed Central Ltd. This is an Open Access article distributed under the terms of the Creative Commons Attribution License (http://creativecommons.org/licenses/by/2.0), which permits unrestricted use, distribution, and reproduction in any medium, provided the original work is properly cited. 